\title{
COMPARISON OF METFORMIN AND ORAL CONTRACEPTIVE PILLS IN THE TREATMENT OF POLYCYSTIC OVARIAN SYNDROME
}

\author{
Rabia Mushtaq, Sadaf Iqbal*, Afroza Abbas, Bushra Iftikhar**, Waqas Ahmed ${ }^{* * *}$, Afeera Afsheen ${ }^{* * * *}$ \\ Sargodha Medical College, Sargodha Pakistan, *Combined Military Hospital Hyderabad/National University of Medical Sciences (NUMS) Pakistan, **Pakistan \\ Naval Ship Shifa Hospital, Karachi Pakistan, ${ }^{* * *} 144$ Medical Battalion/National University of Medical Sciences (NUMS) Pakistan, ${ }^{* * *}$ Combined Military Hospital \\ Multan/National University of Medical Sciences (NUMS) Pakistan
}

\begin{abstract}
Objective: To compare metformin and oral contraceptive pills in terms of mean change of serum testosterone levels and body mass index in polycystic ovarian syndrome.

Study Design: Quasi experimental study.

Place and Duration of Study: Department of Gynecology and Obstetrics, Sargodha Medical College, Sargodha Pakistan, from Apr to Dec 2019.

Methodology: A total of 64 patients presenting with polycystic ovarian syndrome between 15-35 years were included. All patients were divided into two groups i.e. group 1 received oral contraceptive pills, and group 2 received metformin. Patients were clinically evaluated at baseline and 6 months after initial presentation to address the primary aim of evaluating the change in mean serum testosterone levels and body mass index after treatment.

Results: The mean age of patients was $20.30 \pm 4.92$ years. The mean body mass index of patients at presentation was 30.32 $\pm 2.66 \mathrm{~kg} / \mathrm{m}^{2}$. The mean reduction in the level of testosterone in group 1 was $5.14 \pm 0.35 \mathrm{ng} / \mathrm{ml}$ while in group 2 it was $2.58 \pm$ $0.41 \mathrm{ng} / \mathrm{ml}(p<0.001)$ which was statistically significant. Mean decrease in body mass index in group $1 \mathrm{was} 1.51 \pm 0.71 \mathrm{~kg} / \mathrm{m}^{2}$ while in group 2 was $1.29 \pm 0.46 \mathrm{~kg} / \mathrm{m}^{2}(p=0.148)$ which was statistically insignificant.

Conclusion: Oral contraceptive pills were better than metformin in terms of mean decrease in serum testosterone levels in women presenting with polycystic ovarian syndrome while the mean reduction in body mass index in both the groups was similar.
\end{abstract}

Keywords: Body mass index, Metformin, Oral Contraceptives, Polycystic ovary syndrome, Testosterone.

This is an Open Access article distributed under the terms of the Creative Commons Attribution License (https://creativecommons.org/licenses/by-nc/4.0/), which permits unrestricted use, distribution, and reproduction in any medium, provided the original work is properly cited.

\section{INTRODUCTION}

First described in 1935, Polycystic ovarian syndrome (PCOS) is amongst the most common disorders of the endocrine system affecting women of the reproductive age group across the globe an approximate prevalence of 3.4-6.6\% in the United States and 6.5-8\% in European studies ${ }^{1-4}$. A much higher prevalence of PCOS has been reported amongst the Pakistani women $(52 \%)$ as compared to a prevalence of $20-25 \%$ in the women population of the United Kingdom ${ }^{5}$. It was the most common cause of hospital admissions for abnormal uterine bleeding in adolescent females ${ }^{6}$. Insulin resistance and obesity further aggravate the severity of the presentation?.

Management of PCOS is aimed at regularization of menstrual cycles along with ovarian testosterone suppression keeping in view the adverse effects profile of the various treatment options ${ }^{8,9}$. One of the characteristic feature of PCOS is that approximately $50-70 \%$ of the patients suffer from variable spectrums of insulin resistance ranging from full blown diabetes mellitus

Correspondence: Dr Rabia Mushtaq, Obs \& Gynae Department, Sargodha Medical College, Sargodha Pakistan

Received: 26 Sep 2020; revised received: 06 Nov 2020; accepted: 09 Nov 2020 to insulin resistance. The hyperinsulinemia in patients with PCOS predisposes them to many cardiovascular and cerebrovascular diseases, metabolic syndrome, hypertension, and diabetes mellitus ${ }^{10}$.

Metformin is an insulin-sensitizing drug that has demonstrated promise in therapy for patients with PCOS while oral contraceptive pills ( $\left.\mathrm{OCP}^{\prime} \mathrm{s}\right)$ have been the traditional go to option for patients with hyperandrogenism ${ }^{7,9}$. The mechanism of action of metformin is mediated through increase in the insulin sensitivity, augmented secretion of estrogens, a reduction in the androgen levels and increased production of sex hormone binding globulin (SHBG) ${ }^{7}$.

OCPs cause a reduction in the circulating the levels of excess androgenic hormones by increase in the direct negative feedback signals on the LH secretion, and the net result is a decreased synthesis of androgens from the ovaries. Furthermore, they increase liver production of sex hormone binding globulin (SHBG) subsequently leading to increased binding of circulating free androgens and decreasing their levels ${ }^{9}$.

Keeping in view the magnitude of the problem and the limited number of studies available from Pakistan on this topic, this study was devised with the 
objective of this study was to compare metformin and OCPs in terms of mean change of serum testosterone levels and body mass index (BMI) in PCOS. The rationale of the study was to determine the better drug for lowering the testosterone levels in women with PCOS in our setup since the previous studies have had variable outcomes.

\section{METHODOLOGY}

A quasi experimental study was conducted on a total of 64 patients reporting to Government Mian Mola Buksh Hospital Sargodha and University medical and diagnostic center, Sargodha were enrolled in the study after taking permission from hospital ethical review committee (IRB certificate number: UOS/SMC/ 715/2019). Written informed consent was taken from all patients included in the study. The sample size calculated using WHO sample size calculator by taking level of significance as $5 \%$; power of test $=95 \%$; population standard deviation $=3.5^{11}$; variance $=12.2511$; test value of population mean $=7.711$, and anticipated population mean $=4.8^{11}$. The sample size came out to be 32 patients in each group, with a total sample size was 64 patients. The sampling technique was non-probability consecutive sampling.

The inclusion criteria included patients presenting with polycystic ovaries on vaginal ultrasound examination ( $\geq 8$ sub capsular follicles, $3-8 \mathrm{~mm}$ in diameter involving one ovary along with increased stroma) and any one of the symptoms including clinical manifestations of hyperandrogenism, oligomenorrhea or amenorrhea, and/or an elevated serum testosterone level, at least 2 years post-menarche and age between 15-35 years. The exclusion criteria included patients with personal or family history of coagulopathies, pregnancy, severe migraines with aura, hypertension, breast cancer, and smoking.

Patients were divided into 2 groups; group 1 and group 2 containing 32 patients each by lottery method. The baseline serum testosterone levels and BMI were calculated for all patients. Group 1 patients recei-ved oral contraceptive pill $\{30 \mu \mathrm{g}$ ethinyl estradiol $\pm 0.15 \mathrm{mg}$ levonorgestril (once daily) $\}$ as a monthly regimen of 21 days followed by iron supplements for 7 days for 6 months. Group 2 patients received metformin at a dose of $1000 \mathrm{mg}$ twice daily for 6 months. Serum testosterone levels of the both groups was again determined after 6 months along with BMI. Data in both groups was recorded on a predesigned questionnaire.

Data was analyzed by using SPSS-23. For numerical variables including age, serum testosterone levels and BMI, mean and standard deviation were calculated. Efficacy of drugs in terms of mean change in serum testosterone levels and mean reduction in BMI was compared between the two groups using independent sample t-test. The $p$-value $\leq 0.05$ was taken as statistically significant.

\section{RESULTS}

A total of 64 patients were included in the study. The mean age of patients was $20.30 \pm 4.93$ years. The mean age of patients in group 1 was $19.74 \pm 4.52$ years and in group 2 was $20.86 \pm 5.30$ years. Majority of the patients $(64.06 \%)$ were between $15-20$ years of age. The mean BMI of patients was $30.32 \pm 2.66 \mathrm{~kg} / \mathrm{m}^{2}$. The mean BMI at the time of presentation and after six months of treatment is shown in table-I.

The mean levels of testosterone at the time of presentation and after six months of treatment are shown in table-II. The mean reduction in the levels of testosterone and BMI after six months of treatment (table-III).

Table-I: Distribution of patients according to body mass index at presentation and after 6 months of treatment.

\begin{tabular}{l|c|c|c}
\hline $\begin{array}{l}\text { Body Mass } \\
\text { Index } \mathbf{( k g / \mathbf { m } ^ { 2 } )}\end{array}$ & $\begin{array}{c}\text { Group 1 } \\
(\mathbf{n = 3 2})\end{array}$ & $\begin{array}{c}\text { Group 2 } \\
(\mathbf{n = 3 2})\end{array}$ & $\begin{array}{c}\text { Total } \\
(\mathbf{n}=\mathbf{6 4})\end{array}$ \\
\hline \multirow{2}{*}{ At Presentation } & $30.08 \pm$ & $30.55 \pm$ & $30.32 \pm$ \\
& 2.76 & 2.58 & 2.66 \\
\hline \multirow{2}{*}{ After 6 months } & $28.57 \pm$ & $29.29 \pm$ & $28.93 \pm$ \\
& 2.54 & 2.52 & 2.54 \\
\hline
\end{tabular}

Table-II: Distribution of patients according to according to mean levels of testosterone $(\mathrm{ng} / \mathrm{ml})$.

\begin{tabular}{l|c|c|c}
\hline $\begin{array}{l}\text { Mean levels of } \\
\text { testosterone } \\
(\mathbf{n g} / \mathrm{ml})\end{array}$ & $\begin{array}{c}\text { At } \\
\text { Presenta- } \\
\text { tion }\end{array}$ & $\begin{array}{c}\text { After 6 } \\
\text { Months }\end{array}$ & Reduction \\
\hline Group 1 $(\mathrm{n}=32)$ & $9.54 \pm 0.29$ & $4.40 \pm 0.37$ & $5.14 \pm 0.35$ \\
\hline Group 2 $(\mathrm{n}=32)$ & $9.59 \pm 0.37$ & $6.98 \pm 0.36$ & $2.58 \pm 0.41$ \\
\hline $\begin{array}{l}\text { Table-III: Mean decrease in levels of testosterone and } \\
\text { body mass index in both groups. }\end{array}$ \\
\hline Variable & Group 1 & Group 2 & p-value \\
\hline Reduction in & $\begin{array}{c}5.14 \pm \\
\text { testosterone }(\mathrm{ng} / \mathrm{ml})\end{array}$ & $\begin{array}{c}2.57 \pm \\
0.41\end{array}$ & $<0.001$ \\
\hline $\begin{array}{l}\text { Decrease in Body } \\
\text { Mass Index }\left(\mathrm{kg} / \mathrm{m}^{2}\right)\end{array}$ & $\begin{array}{c}1.51 \pm \\
0.71\end{array}$ & $\begin{array}{c}1.29 \pm \\
0.46\end{array}$ & 0.148 \\
\hline
\end{tabular}

\section{DISCUSSION}

An estimated $50 \%$ of the patients with PCOS have their BMI in the obese range. While the levels of testosterone are a good predictor of the severity of the disease $^{12}$. The decrease in the BMI and levels of testosterone are thus important factors assessing the outcomes of patients undergoing treatment ${ }^{13-16}$. Our results showed a statistically significant mean reduction in the level of testosterone in $\mathrm{OCP}^{\prime} \mathrm{s}$ group versus the metformin group $(p<0.001)$. The mean decrease in BMI was 
also more in the $\mathrm{OCP}^{\prime} \mathrm{s}$ group but the difference was statistically non-significant $(p=0.148)$. A Cochrane review by Tang et al, reported that metformin reduced the levels of testosterone and insulin in women suffering from $\mathrm{PCOS}^{17}$.

A study by Mhao et al, in 2015 found that treatment with metformin reduced the serum testosterone levels from $0.956 \pm 0.31$ to $0.486 \pm 0.29 \mathrm{mg} / \mathrm{dl}$ which was statistically significant $(p=0.038)$ as opposed to a decrease in testosterone levels from $1.177 \pm 0.62$ to $0.850 \pm 0.3 \mathrm{mg} / \mathrm{dl}$ with OCPs which was statistically insignificant $(p=0.132)$. The mean decrease in BMI was from $27.23 \pm 5.44$ to $26.12 \pm 5.53 \mathrm{~kg} / \mathrm{m}^{2}$ in the metformin group $(p=0.000)$ as opposed to a decrease from $30.50 \pm 5.31$ to $29.58 \pm 5.02(p=0.048)$ in the OCPs group $^{18}$.

On the contrary, Al-Zubeidi et al, in 2015 compared the metformin and $\mathrm{OCP}^{\prime} \mathrm{s}$ groups at baseline and then after treatment of 6 months and reported that a statistically not significant decrease in serum testosterone levels from $9.7 \pm 3$ to $7.7 \pm 4 \mathrm{pg} / \mathrm{ml}$ with metfor$\min (p=0.15)$ compared to a statistically significant decrease in serum testosterone levels from 9.1 to $4.8 \pm 4 \mathrm{pg}$ $/ \mathrm{ml}$ with $\mathrm{OCP}^{\prime} \mathrm{s}(p=0.046)$. The study also reported a mean decrease in BMI from $33.7-31.9 \mathrm{~kg} / \mathrm{m}^{2}$ in patients taking metformin $(p=0.004)$ and a mean reduction in BMI from 33.4 to $32.9 \mathrm{~kg} / \mathrm{m}^{2}$, in those taking OCPs $(p=0.045)^{11}$.

In 2018, Kumar et al, reported that the mean BMI in the OCP's group decreased by $0.5 \mathrm{~kg} / \mathrm{m}^{2}$ which was statistically insignificant $(p=0.273)$. The mean BMI in metformin group increased by $1.1 \pm 0.1 \mathrm{~kg} / \mathrm{m}^{2}$ which was also statistically insignificant $(p=0.383)$ which was comparable to our results. The mean reduction in levels of testosterone in the $\mathrm{OCP}^{\prime} \mathrm{s}$ group was $0.16 \pm$ $0.07 \mathrm{ng} / \mathrm{ml}$ which was statistically significant $(p<0.001)$ whereas the mean reduction in levels of testosterone in the metformin group was from $0.04 \pm 0.01 \mathrm{ng} / \mathrm{ml}$ which was statistically not significant $(p=0.224)^{19}$. Suvarna et al, in 2016 reported that the two groups did not differ significantly in terms of decrease in serum testosterone levels $(p=0.65)^{20}$.

Despite the fact that OCPs were found to be a better treatment option, it is pertinent to mention that some patients' especially unmarried girls are reluctant to take OCPs when prescribed due to the social taboo attached in our population. However, better counseling of the patients as well as the parents can help with the treatment. The limitation of our study was the small sample size. We recommend further research protocols with larger sample sizes to help devise evidence based research protocols from the data obtained from the local population.

\section{CONCLUSION}

OCPs were better than metformin in terms of mean decrease in serum testosterone levels while the decrease in BMI was found to be similar in both the groups in patients presenting with PCOS. The reduction in BMI was greater with $\mathrm{OCP}^{\prime} \mathrm{s}$ than metformin although by a non-significant difference statistically. Therefore, we recommend the use of OCPs for the treatment of female patients presenting with PCOS.

\section{CONFLICT OF INTEREST}

This study has no conflict of interest to be declared by any author.

\section{REFERRENCES}

1. Wolf WM, Wattick RA, Kinkade ON, Olfert MD. Geographical prevalence of polycystic ovary syndrome as determined by region and race/ethnicity. Int J Environ Res Public Health 2018; 15(11): 2589-92.

2. Engmann L, Jin S, Sun F, Legro RS, Polotsky AJ, Hansen KR, Racial and ethnic differences in the polycystic ovary syndrome metabolic phenotype. Am J Obstet Gynecol 2017; 216(5): e1-13.

3. Azziz R, Woods KS, Reyna R, Key TJ, Knochenhauer ES, Yildiz $\mathrm{BO}$. The prevalence and features of the polycystic ovary syndrome in an unselected population. J Clin Endocrinol Metab 2004; 89(6): 2745-49.

4. Asunción M, Calvo RM, San Millán JL, Sancho J, Avila S, Escobar-Morreale HF. A prospective study of the prevalence of the polycystic ovary syndrome in unselected Caucasian women from Spain. J Clin Endocrinol Metab 2000; 85(7): 2434-38.

5. Akram M, Roohi N. Endocrine correlates of polycystic ovary syndrome in Pakistani women. J Coll Physicians Surg Pak. 2015;25(1):22-6.

6. Maslyanskaya S, Talib HJ, Northridge JL, Jacobs AM, Coble C, Coupey SM. Polycystic ovary syndrome: an under-recognized cause of abnormal uterine bleeding in adolescents admitted to a children's hospital. J Pediatr Adolesc Gynecol 2017; 30(3): 349-55.

7. Ainuddin JA, Kazi S, Aftab S, Kamran A. Metformin for preventing gestational diabetes in women with polycystic ovarian syndrome. J Coll Physicians Surg Pak 2015; 25(4): 237-41.

8. Sheehan MT. Polycystic ovarian syndrome: diagnosis and management. Clin Med Res 2004; 2(1): 13-27.

9. Badawy A, Elnashar A. Treatment options for polycystic ovary syndrome. Int J Womens Health 2011; 3(1): 25-35.

10. Diamanti-Kandarakis E, Dunaif A. Insulin resistance and the polycystic ovary syndrome revisited: an update on mechanisms and implications. Endocr Rev 2012; 33(6): 981-30.

11. Al-Zubeidi $\mathrm{H}$, Klein KO. Randomized clinical trial evaluating metformin versus oral contraceptive pills in the treatment of adolescents with polycystic ovarian syndrome. J Pediatr Endocrinol Metab 2015; 28(7-8): 853-58.

12. Rosenfield RL, Ehrmann DA. The pathogenesis of polycystic ovary syndrome (pcos): the hypothesis of pcos as functional ovarian hyperandrogenism revisited. Endocr Rev 2016; 37(5): 467-20.

13. Lanzo E, Monge M, Trent M. Diagnosis and Management of Polycystic Ovary Syndrome in Adolescent Girls. Pediatr Ann 2015; 44(9): e223-30. 
14. Mc Cartney CR, Marshall JC. Practice C. Polycystic ovary syndrome. N Engl J Med 2016; 375(1): 54-64.

15. Johnson NP. Metformin use in women with polycystic ovary syndrome. Ann Transl Med 2014; 2(6): 56-60.

16. PCOS Society (India). Consensus Statement on the use of oral contraceptive pills in polycystic ovarian syndrome women in India. J Hum Reprod Sci 2018; 11(2): 96-18.

17. Tang T, Lord JM, Norman RJ, Yasmin E, Balen AH. Insulin-sensitising drugs (metformin, rosiglitazone, pioglitazone, D-chiroinositol) for women with polycystic ovary syndrome, oligo amenorrhoea and subfertility. Cochrane Database Syst Rev 2012; 5(1): CD003053.

18. Mhao NS, Al-Hilli AS, Hadi NR, Jamil DA, Al-Aubaidy HA. A comparative study to illustrate the benefits of using ethinyl estradiol-cyproterone acetate over metformin in patients with polycystic ovarian syndrome. Diabetes Metab Syndr 2016; 10 (Suppl-1): S95-8.

19. Kumar Y, Kotwal N, Singh Y, Upreti V, Somani S, Hari Kumar KVS. A randomized, controlled trial comparing the metformin, oral contraceptive pills and their combination in patients with polycystic ovarian syndrome. J Family Med Prim Care 2018; 7(3): 551-56.

20. Suvarna Y, Maity N, Kalra P, Shivamurthy M. Comparison of efficacy of metformin and oral contraceptive combination of ethinyl estradiol and drospirenone in polycystic ovary syndrome. J Turk Ger Gynecol Assoc 2016; 17(1): 6-9. 